\title{
Retrospective Study to Compare the Usefulness, Efficacy and End result of SICS with Rigid IOL, over Clear Corneal Phacoemulsification with Foldable Lens Implantation
}

\author{
Author \\ Dr K.M Suresh, MBBS, MS (OPH) \\ Medical Director Vidya Eye Hospital \\ \# 47/E,15 ${ }^{\text {th }}$ Main, MC Road, Vijayanagar, Bangalore 560040 \\ Email: drkmsuresh@hotmail.com PH.23389854,Mob: 9845378853 \\ Website: www.vidyaeyehospital.com
}

\begin{abstract}
Aim: of the study is to establish whether the manual SICS (Small Incision Cataract Surgery) with rigid IOL(Intra Ocular Lens) implantation has the same end result compared to Clear Corneal Phacoemulsification with foldable IOL implantation.

Materials and Methods: This is a retrospective study with analysis of data of 100 patients operated by Phacoemulsification with foldable lens implantation method, categorized as Group 1. The other 100 Patients who underwent Small Incision Cataract Surgery with rigid IOL were categorized into Group 2. The results were then compared.

Results: It is observed that more than $82 \%$ in both the groups were having unaided vision better than 6/18. Cases of BCVA of 6/6 were 99 and 97 in Group1 and Group2 respectively. No significant difference was observed in both groups.

Conclusion: Hence it can be concluded that the manual SICS with rigid IOL has the same end result as that of Clear Corneal Phacoemulsification with foldable IOL implantation.
\end{abstract}

\section{Materials and Methods}

Data of 200 patients who were operated between February 2010 and November 2015 in our centre were selected for the study. The data of the patients who were operated by Phacoemulsification with foldable lens implantation and who were 100 in number were categorized into Group 1. The patients who underwent Small Incision Cataract Surgery (SICS) were categorized into Group 2. Both the groups had patients aged between 50 years to 80years. The cases which had only cataract with no other ocular diseases, and no preoperative astigmatism were selected for the study. Hypermature cataracts were excluded from the study All 200 patients were operated by the same eye surgeon, in the same surgical set up. Group1 had undergone clear corneal phacoemulsification with foldable lens implantation. $3.2 \mathrm{~mm}$ incision at $12 \mathrm{o}$ ' clock meridian was done in the clear cornea and foldable IOL implantation was done under topical anaesthesia.

Group 2 patients had undergone SICS with $6.5 \mathrm{~mm}$ smile incision with rigid IOL under topical anaesthesia. 
The patients' postoperative data were tabulated on the $1^{\text {st }}$ postoperative day, $1^{\text {st }}, 2^{\text {nd }}, 3^{\text {rd }}, 4^{\text {th }}$, and $5^{\text {th }}$ postoperative weeks. The unaided vision, best corrected visual acuity (BCVA) and the amount of astigmatism induced by the surgery were noted at the end of the fifth week to conclude the amount of astigmatism, induced in operated cases by both the methods of surgery.

When posterior capsular tear and vitreous loss were encountered, anterior vitrectomy was done and posterior chamber IOL implantation was done on the remnants of anterior and posterior capsules. In cases where there was no sufficient support, clean anterior vitrectomy was done and primary anterior chamber IOL implanted. Postoperative unaided vision, BCVA, RRR pupil, per-operative, postoperative complaints or discomfort, operative and postoperative complications encountered, duration taken for stabilization of vision were taken as the criteria to compare Group1 and Group2

\section{Results}

We observed that in 200 patients who were selected for the study, in group1 which consisted of 100 patients who underwent clear corneal phacoemulsification with foldable lens implantation there were 88 patients $(88 \%)$ who had unaided visual acuity of better than 6/18 after $5^{\text {th }}$ week of postoperative period, vitreous loss was observed in 5 cases $(5 \%)$, posterior capsular rupture seen in 5 cases (5\%), postoperative astigmatism was induced by surgery in 3 cases (3\%), 99 cases (99\%) had BCVA $6 / 6$ in the $5^{\text {th }}$ week. Only one case did not improve to $6 / 6$ with best correction due to high astigmatism induced by the surgery.

In group 2 almost a similar set of results were observed. In group 2 after $5^{\text {th }}$ week of surgery 82 patients $(82 \%)$ had unaided visual acuity of better than $6 / 18$, Vitreous loss was observed in 6 cases $(6 \%)$, Posterior capsular rupture was seen in 6cases $(6 \%)$ postoperative astigmatism was induced in 5 cases (5\%), the BCVA was $6 / 6$ in 97cases (97\%), while 3cases did not improve to 6/6 with best correction due to the high astigmatism induced by the surgery.

The results are graphically represented in Fig.1. Standard deviation is calculated for each parameter. The values are tabulated in Table 1

There were 2 cases in which we had to do anterior chamber IOL implantation, and 3 cases where posterior IOL implantation were done, among the total of 5 cases of posterior capsular tear encountered in Group1. In Group2 we encountered 6 cases of posterior capsular tear out of which in 4 cases we had no capsular remnant support and hence had to do anterior chamber IOL implantation, in 2 cases posterior chamber IOL were implanted

We also observed that 80 patients $(80 \%)$ in group 2 had vision better than $6 / 18$ on the $1^{\text {st }}$ post-operative day, while only 68 patients $(68 \%)$ had vision better than $6 / 18$ on the $1^{\text {st }}$ postoperative day in group1, this difference was due to the ultrasonic heat energy induced corneal oedema in group1 patients.

Per operative subjective experience with topical anaesthesia were similar in both groups. Postoperative discomforts experienced by both the groups were same

One more observation was in favour of clear corneal phacoemulsification with foldable lens implantation i.e.,Round and regular pupils were more in number, 90(90\%) cases in Group1 while round and regular pupils were found only in 80 cases $(80 \%)$ in group2. Stabilisation of vision occurred on the $5^{\text {th }}$ week of post-operative period in both the groups. 
Table 1

\begin{tabular}{|l|l|l|l|}
\hline Parameters & Group1 & Group2 & $\begin{array}{l}\text { Standard } \\
\text { Deviation }\end{array}$ \\
\hline $\begin{array}{l}\text { Vision better } \\
\text { than6/18 }\end{array}$ & 88 & 82 & 3 \\
\hline Vitreous Loss & 5 & 6 & 0.5 \\
\hline $\begin{array}{l}\text { Posterior Capsular } \\
\text { Tear }\end{array}$ & 5 & 6 & 0.5 \\
\hline $\begin{array}{l}\text { Postoperative } \\
\text { Astigmatism induced }\end{array}$ & 3 & 5 & 1 \\
\hline $\begin{array}{l}\text { BCVA 6/6 after 5 } \\
\text { postoperative week }\end{array}$ & 99 & 97 & 1 \\
\hline
\end{tabular}

\section{Discussion}

India has got a majority of socio-economically weaker individuals even in urban areas. It becomes extremely difficult for the people in geriatric age group to sustain the enormous escalation of the medical or surgical bills, which in fact become inevitable due to the fast growing innovations and technologies in the medical field. Hence it becomes an innate responsibility of an ophthalmologist to devote and dedicate his time to replace the expensive scientific knowhow with an affordable and meantime an uncompromising, simple and affordable technique to reach the needs of this section of the society. Further it becomes the foremost responsibility of the ophthalmic surgeon to unequivocally vouch for the good end result of the less expensive surgery, which becomes an inevitable choice of the underprivileged. Hence this study was aimed at determining whether cost benefit ratio in SICS with rigid IOL was on positive shift compared to the same in Phacoemulsification with foldable IOL implantation. It can be noted that the cost in group1 is almost 3times the cost incurred in group 2. At the meantime study concentrated not only on the parameters mentioned above, but also on the quality of postoperative results observed in all the individuals who underwent, surgery in group 2 as compared to group1.

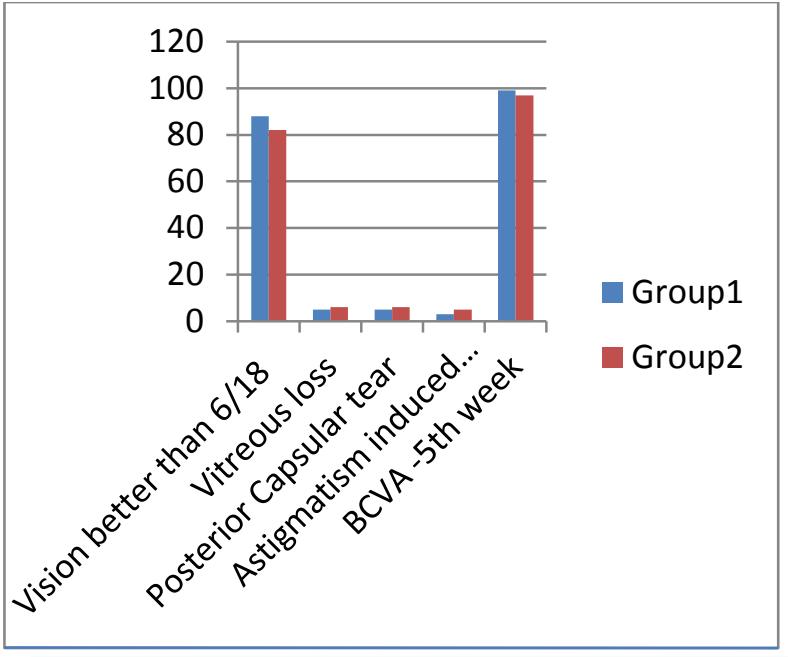

Figure 1- parameters in X-axis; no., of patients in Y-axis.

Interestingly,a trial ${ }^{[11]}$ was conducted in 2005 that compared the one of the world's foremost phacoemulsification surgeons, at the University of California - San Francisco, who used the highest levels of technology available in the Western world, versus method of small incision sutureless cataract surgery, requiring an operating microscope as the only high technology instrument used in remote cataract outreach programs for the poorest people in Nepal. The results from this trial were considered "dramatic." The initial investment for first method was more than $\$ 100,000$ USD for instruments and equipment in contrast to less than $\$ 15,000$ for all the equipment needed to perform SICS. The results equalized in six weeks, when there were no statistical differences in the outcomes. In both groups, $98 \%$ of the patients returned to excellent vision. It can be noticed that in our study also more than $95 \%$ of patients who underwent SICS with rigid IOL had BCVA of $6 / 6$.

One more study ${ }^{[15]}$ - A Comparative Study of Clear Corneal Phacoemulsification with Rigid IOL Versus SICS; the Preferred Surgical Technique in Low Socio-economic group

Patients of Rural Areas- conducted by Jaya devendra, et.all concluded as follows: SICS may be the more appropriate surgical procedure for 
the treatment of cataract in high volume camp surgery of rural, low socio economic group patients in the developing world as compared to clear corneal phaco with rigid IOL. It is quicker, cost effective, and gives good visual results, while being non machine dependent. Enlarging the clear corneal incision to implant a rigid IOL is not a good surgical option, as it gives higher astigmatism, as well as a less secure wound. SICS should be the preferred option in rural patients who cannot afford a foldable IOL.

Yet another study [16] done by RB Khandekar et al., it was established that more than $87 \%$ of patients who underwent SICS had vision better than $6 / 18$ after $4^{\text {th }}$ postoperative week. In our study also this point was categorically established.

Our study which involves 100 patients in Group1 and 100 patients in group2, 88\% had good unaided visual acuity and $99 \%$ had BCVA of $6 / 6$ in group1, while $82 \%$ had good unaided visual acuity and $97 \%$ had BCVA of $6 / 6$ in group2. There was no significant difference in the number of cases in which the per-operative complications like posterior capsular tear and vitreous loss that occurred in both the groups. The patients of group2 almost saved more than $2 / 3$ rds the cost of surgery incurred by the Group1 patients, still not compromising in the quality of vision enjoyed. The fact that we could still implant posterior chamber IOL in many cases of posterior capsular tear in Group1, indeed heralds the fact that the remnants of anterior and posterior capsules are much stable in Group1 when compared to group2 cases. The point that the overall cost incurred by group 2 being noticeably minimum but the end result being almost the same, overcomes this deficiency of group2 when compared to Group1 cases.

\section{Conclusions}

By observing the statistics and the results of this study it is rather evident that the end result of the goup2 patients who underwent SICS with rigid IOL, was not very far from the overall result of group1 patients. The mean and standard deviations in each parameter, prove this point. Eventhough the patients who underwent clear corneal phacoemulsification with foldable lens implantation, enjoyed the benefits of no blood, no bandage surgeries, there were no significant differences in the various parameters considered for this study in both the groups. Both the groups enjoyed the benefits of no pain, no injection cataract operation, as all 200 surgeries were done under topical anaesthesia. End result being with no significant difference(see Table1), the SICS with rigid intraocular lens implantation is having the same end result, efficacy, usefulness in terms of both safety, and comfort when compared to Clear Corneal Phacoemulsification with foldable intraocular lens implantation. SICS with rigid IOL implantation is on the positive side of the cost benefit ratio. Hence SICS with rigid IOL implantation can be used as a safe and rewarding procedure for economically weaker individuals

\section{Acknowledgement}

I hereby thank all my junior medical staff and paramedical staff who helped me in assessing the operative and postoperative outcomes of all the cases, included in this study.

I sincerely thank my students who helped me in representing the results, in a statistical format.

\section{References}

1. A Hennig, LR Puri, H Sharma, JR Evans, D Yorston. Foldable vs rigid lenses after phacoemulsification for cataract surgery: a randomised controlled trial. Eye (Lond) 2014;28(5):567-75. [PMC free article] [PubMed]

2. B Reddy, A Raj, VP Singh. Site of Incision and Corneal Astigmatism in 
Conventional SICS versus

Phacoemulsification. Ann Ophthalmol. 2007;39(3):209-16. [PubMed]

3. VK Mallik, S Kumar, R Kamboj, C Jain, $\mathrm{K}$ Jain, $\mathrm{S}$ Kumar. Comparison of astigmatism following manual small incision cataract surgery: superior versus temporal approach. Nepal J Ophthalmol.2012;4(1):54-58. [PubMed]

4. T Oslen, M Dam- Johanson, T Bek, JO Hjortdal. Corneal versus scleral tunnel incision in cataract surgery: a randomized study. J Cataract Refract Surg. 1997;23:337-41. [PubMed]

5. RF Steinert, SF Brint, SM White, IH Fine. Astigmatism after small incision cataract surgery. A prospective, randomized, multicenter comparison of 4- and 6.5-mm incisions. Ophthalmology. 1991;98(4):417-23. [PubMed]

6. S Archana, AK Khurana, U Chawla. A comparative study of sclero-corneal and clear corneal tunnel incision in manual small-incision cataract surgery. Nepal J Ophthalmol.2011;3(1):19-22. [PubMed]

7. BA Cooper, NM Holekamp, G Bohigian, PA Thompson. Case-control study of endophthalmitis after cataract surgery comparing scleral tunnel and clear corneal wounds. Am J Ophthalmol. 2003;136(2):300-05. [PubMed]

8. Hennig A, Kumar J, Yorston D, Foster A. Sutureless cataract surgery with nucleus extraction - outcome of a prospective study in Nepal. $\mathrm{Br} \quad \mathrm{J}$ Ophthalmol 2003;87(3):266-270.

9. Singh R, Vasavada AR, Janaswamy G. Phacoemulsification of brunescent and black cataracts. J Cataract Refract Surg 2001;27(11):1762-1769.

10. Gogate PM, Kulkarni SR, Krishnaiah S, Deshpande RD, Joshi SA, Palimkar A. Safety and efficacy of

phacoemulsification compared with manual small incision cataract surgery by a randomized controlled clinical trial - six week results. Ophthalmology 2005;112(5):869-874.

11. Ruit SA, Tabin G, Chang D, Bajracharya L, Kline DC, Richheimer W. A prospective randomised clinical trial of phacoemulsification vs manual sutureless small incision extracapsular cataract surgery in Nepal. Am J Ophthalmol 2007;143(1):32-38.

12. Venkatesh R, Tan C, Sengupta S, Ravindran R, Krishnan K, Chang D. Phacoemulsification versus manual small incision cataract surgery for white cataract. J Cataract Refract Surg 2010;36:1849-1854.

13. Devereaux PJ, Bhandari M, Clarke M, et al. Need for expertise based randomised controlled trials. Br Med J 2005;330:88.

14. Bourne R, Minassian D, Dart J, Rosen P, Kaushal S, Wingate N. Effect of cataract surgery on the corneal endothelium modern phacoemulsification compared with extracapsular cataract surgery. Ophthalmology 2004;111(4):679-685. Accepted 31 January 2012.

15. Jaya Devendra, Smitha Agarwal and Pankaj Kumar Singh A Comparative Study of Clear Corneal Phacoemulsification with Rigid IOL Versus SICS; the Preferred Surgical Technique in Low Socio-economic group Patients of Rural Areas J Clin Diagn Res. 2014 Nov; 8(11): VC01-VC03.

16. RB Khandekar, BK Jain, AK Sudhan, KP Pandey. Visual acuity at 6 weeks after small incision cataract surgery and role of audit in predicting visual acuity. Eur J Ophthalmol. 2010;20(2):345-52. [PubMed]

17. Comparative outcomes of manual small incision cataract surgery and 
phacoemulsification performed by ophthalmology trainees in a tertiary eye care hospital in India: a retrospective cohort design Rohit C Khanna ${ }^{1}$,Srivalli Kaza ${ }^{1}$,Ghanshyam Palamaner Subash Shantha $^{2}$,Virender S Sangwan ${ }^{3}$ BMJ Open 2012;2:e001035 doi:10.1136/bmjo pen-2012-001035 